Provided for non-commercial research and education use. Not for reproduction, distribution or commercial use.

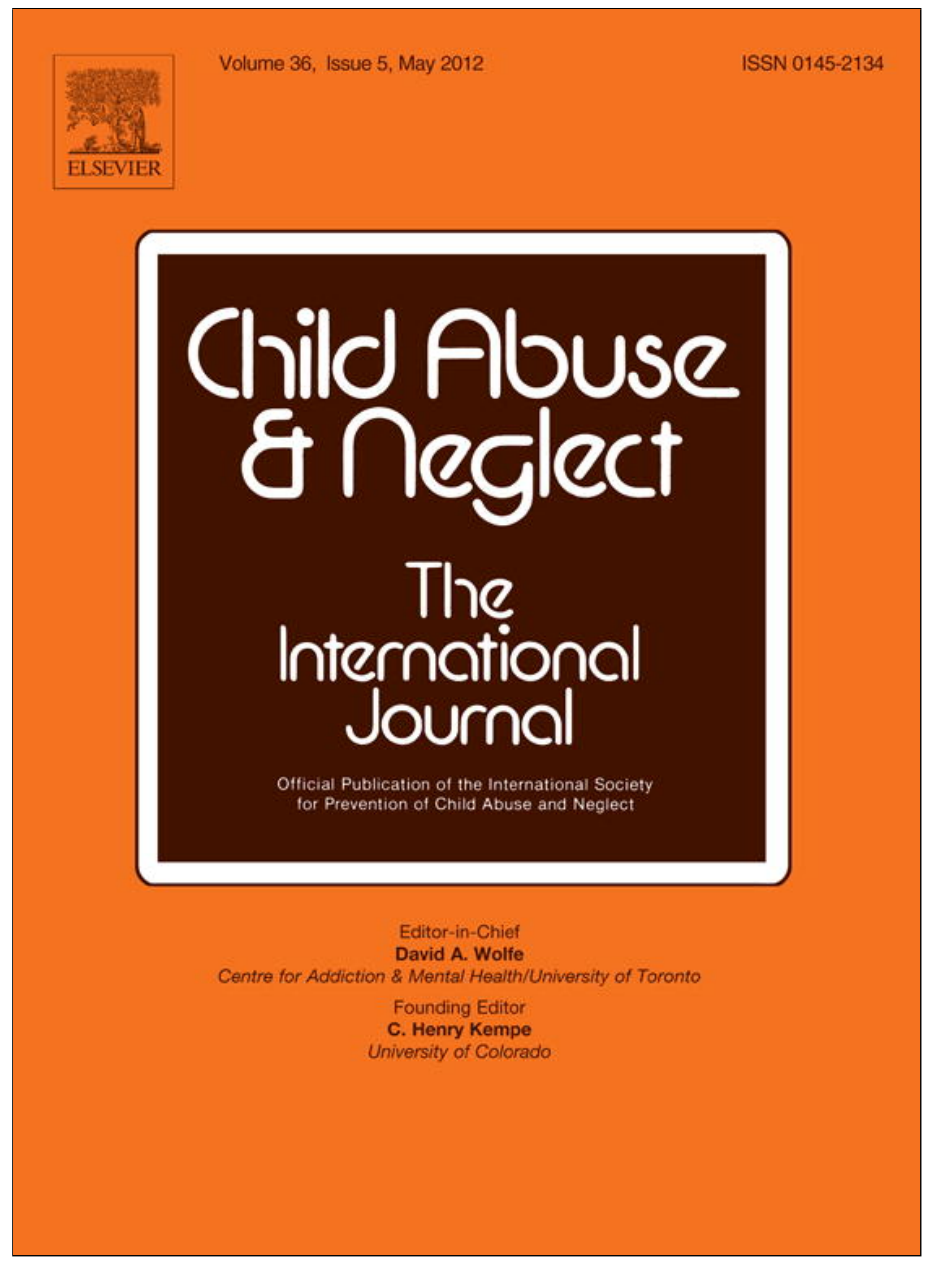

This article appeared in a journal published by Elsevier. The attached copy is furnished to the author for internal non-commercial research and education use, including for instruction at the authors institution and sharing with colleagues.

Other uses, including reproduction and distribution, or selling or licensing copies, or posting to personal, institutional or third party websites are prohibited.

In most cases authors are permitted to post their version of the article (e.g. in Word or Tex form) to their personal website or institutional repository. Authors requiring further information regarding Elsevier's archiving and manuscript policies are encouraged to visit:

http://www.elsevier.com/copyright 


\title{
Paternal depression and risk for child neglect in father-involved families of young children
}

\author{
Shawna J. Lee ${ }^{\mathrm{a}, *}$, Catherine A. Taylor ${ }^{\mathrm{b}}$, Jennifer L. Bellamy ${ }^{\mathrm{c}}$ \\ a School of Social Work and Research Center for Group Dynamics, University of Michigan, 1080 South University Avenue, Ann Arbor, MI 48109, USA \\ b School of Public Health and Tropical Medicine, Tulane University, New Orleans, LA, USA \\ c School of Social Service Administration, University of Chicago, Chicago, IL, USA
}

\section{A R T I C L E I N F O}

\section{Article history:}

Received 18 October 2011

Received in revised form 26 March 2012

Accepted 4 April 2012

Available online 26 May 2012

\begin{abstract}
A B S T R A C T
Objective: To examine the association of paternal depression with risk for parental neglect of young children.

Study design: The sample was derived from a birth cohort study of 1,089 families in which both biological parents resided in the home when the target child was 3- and 5-years old. Prospective analyses examined the contribution of paternal and maternal parenting risks (e.g., depression, alcohol use, and parenting stress) to the incidence of neglect of the target child. Models accounted for a comprehensive set of factors associated with parental child neglect in 2-parent families, including quality of the parental relationship, household economic conditions, and paternal demographic characteristics.

Results: Approximately $12 \%$ of families reported at least 1 instance of neglect; $10 \%$ of fathers were depressed when their child was 3-years old. Rates of paternal and maternal depression were twice as high in families in which child neglect was present. Paternal depression when a child was 3-years old was associated with increased odds of child neglect at age 5 [adjusted odds ratio: 1.94 (95\% confidence interval: 1.18-3.19); $P<.01$ ]. Father-related risks for neglect remained statistically significant after accounting for strong, significant effects of maternal parenting risks, including maternal depression, and household economic hardship. Paternal parenting stress was also associated with heightened risk for neglect, although only at the level of marginal significance after accounting for maternal parenting risks [adjusted odds ratio: 1.40 (95\% confidence interval: $0.97-2.04$ ); $P=.075$ ].

Conclusions: Screening fathers for parenting risks such as depression during well-baby visits and social work intervention to facilitate fathers' help-seeking behaviors related to treatment of depression may help to prevent and reduce risk of neglect.
\end{abstract}

(c) 2012 Elsevier Ltd. All rights reserved.

\section{Introduction}

Neglect, including failure to supervise and failure to provide basic necessities to children, constitutes the majority of charges in Child Protective Services (CPS) cases investigated and substantiated in the US. In 2009, 67\% of all child maltreatment fatalities in the US were related to neglect (US Department of Health and Human Services, 2010). Although rates of substantiated cases of sexual and physical abuse declined from the early 1990 s to 2003 (47\% and 36\%, respectively), the rate of child neglect declined by only 7\% during the same period (Jones, Finkelhor, \& Halter, 2006) and recurrence of neglect was high (Hindley, Ramchandani, \& Jones, 2006). As such, neglect seems to be an especially intractable form of maltreatment, perhaps in part due to the challenges of defining neglect (Dubowitz et al., 2005; English, Thompson, Graham, \& Briggs, 2005)

\footnotetext{
* Corresponding author.
} 
and concordant difficulties in identifying specific mechanisms that can be targeted to reduce or prevent this form of child maltreatment.

Infants and young children are at a higher risk for neglect than older children. National child welfare data indicate that almost $80 \%$ of all maltreatment victims $\leq 5$ years of age are the victims of neglect, as opposed to other forms of maltreatment (e.g., physical abuse) (DeVooght, McCoy-Roth, \& Freudlich, 2011). Children who experience neglect are more likely to develop a variety of poor health and behavioral health outcomes (Gilbert et al., 2009). For example, studies have linked child neglect to internalizing and externalizing behavior problems (Dubowitz, Papas, Black, \& Starr, 2002; Kotch et al., 2008) as well as higher rates of obesity (Whitaker, Phillips, Orzol, \& Burdette, 2007).

National data also indicate that $78 \%$ of children $\leq 14$ months have an involved biological father (Vogel, Boller, Faerber, Shannon, \& Tamis-LeMonda, 2003) and that biological fathers are more likely to be involved in cases of child neglect than other types of child maltreatment (US Department of Health and Human Services, 2010). However, few studies have examined paternal risk factors for child neglect in father-involved households of young children. Most research examining the father's role in maltreatment, including neglect and physical abuse, has focused on the risks represented by the absence of biological fathers (e.g., single mother-headed households) and nonbiological fathers or father figures (e.g., paramours and stepfathers) (Berger, Paxson, \& Waldfogel, 2009; Coohey, 1998; Radhakrishna, Bou-Saada, Hunter, Catellier, \& Kotch, 2001; Stiffman, Schnitzer, Adam, Kruse, \& Ewigman, 2002; Wu et al., 2004).

To address this gap, we focus on child neglect in households where a self-identified biological father is present. The importance of studying risk for child neglect in father-involved families is underscored by the disproportional representation of fathers as perpetrators of child maltreatment. Studies show that male involvement in child maltreatment is higher than would be expected given that, in comparison to mothers, fathers spend far less time caring for young children (Brewster et al., 1998; Fujiwara, Barber, Schaechter, \& Hemenway, 2009; Margolin, 1992; Nobes \& Smith, 2000; Stiffman et al., 2002). National child welfare data indicate that fathers or father surrogates were implicated in half of all of child maltreatment fatalities in which a parent was the perpetrator (US Department of Health and Human Services, 2010, p. 62).

\section{Depression among fathers of young children}

Incidence of depression is highest among parents of babies and toddlers (Davé, Peterson, Sherr, \& Nazareth, 2010). A community-based study of urban families found $7 \%$ of fathers of 1-year-old children were depressed (Davis, Davis, Freed, \& Clark, 2011). Another study in primary care settings found nearly 8\% of fathers with children between 4 and 6 years met diagnostic criteria for depression (Davé, Nazareth, Senior, \& Sherr, 2008). Although the rate of paternal depression was lower than the rate of maternal depression (Davé et al., 2010), these studies suggest that depression is experienced by a significant number of fathers of young children.

As with mothers, depression can compromise parenting among fathers at a developmental period when children are especially vulnerable (Davis et al., 2011; Dubowitz et al., 2011; Mezulis, Hyde, \& Clark, 2004; Paulson, Dauber, \& Leiferman, 2006; Schumacher, Zubaran, \& White, 2008). Paternal parenting stress and depression hinders a father's capacity for supervision, interaction, monitoring, and other positive forms of involvement with his children (Davis et al., 2011; Lee, Perron, Taylor, \& Guterman, 2011; Paulson et al., 2006; Paulson, Keefe, \& Leiferman, 2009; Wanless, Rosenkoetter, \& McClelland, 2008). Paternal depression increases risk for a father's rejection of the child (Elgar, Mills, McGrath, Waschbusch, \& Brownridge, 2007) and has been linked with problems, such as increased alcohol use, that may also be associated with greater levels of child neglect (Davis et al., 2011; Elgar et al., 2007; Lee et al., 2011; Ramchandani et al., 2008).

However, studies have not established a direct link between paternal mental health and risk for child neglect when accounting for potentially confounding maternal characteristics. It is important to examine the unique role of fathers' parenting risks, after accounting for the strong influence of maternal parenting characteristics. One study indicated that infants of depressed mothers who had fathers who exhibited warmth and positive engagement had lower subsequent internalizing behavior problems; however, infants of depressed mothers who also had a depressed, involved father fared considerably worse than those with only a depressed mother (Mezulis et al., 2004). Other studies also suggest that well-functioning fathers may shield children from the influence of poor maternal mental health (Dierker, Merikangas, \& Szatmari, 1999; Kahn, Brandt, \& Whitaker, 2004) indicating the importance of examining the relative contribution of maternal and paternal parenting risks in 2-parent families.

\section{Current study}

We focus on families with fathers living in the household because little is known about the impact of biological fathers on child neglect, particularly in early childhood when incidence of parental depression and child neglect are highest (Davé et al., 2010; DeVooght et al., 2011) and children are most likely to have an involved biological father. The study families were defined as father-involved because all fathers were living in the household at the time of the assessment of child neglect. In addition, all fathers in the study sample self-identified at birth as the biological parent of the study target child. Recognizing that considerable variability exists in fathers' levels of involvement even among residential biological fathers, we control for each father's self-report of involvement in daily care of the child.

The objective of this study was to examine paternal depression as a predictor of child neglect while accounting for known parenting risks for neglect, such as maternal and paternal alcohol use and parenting stress. Maternal and paternal parenting 
risk factors were assessed when children were 3-years old; child neglect by mother and/or the father in the past year was assessed when children were 5 -years old. In addition, we controlled for factors linked to child-neglect risk, including parental relationship quality (Schumacher et al., 2008), household economic conditions, and paternal demographic characteristics (Lee, submitted for publication; Slack et al., 2011). We hypothesized that fathers' depression has a direct influence on risk for subsequent child neglect, even when accounting for potential confounders of maternal parenting risks, paternal alcohol use, and paternal parenting stress.

\section{Method}

Procedures

Data are from the Fragile Families and Child Wellbeing Study (FFCWS), a population-based cohort study that oversampled nonmarital births. Families $(N=4,898)$ were recruited during $1998-2000$ by sampling new births within hospitals from large cities (populations $\geq 200,000$ ); the FFCWS design is described elsewhere (Reichman, Teitler, Garfinkel, \& McLanahan, 2001). The core study interview was conducted with both the mother and the father of the study target child at birth (baseline); parents were re-interviewed when the child was 1-, 3-, and 5-years old. In addition, 2 rounds of supplementary interviews (i.e., the In-Home Longitudinal Study of Pre-School Aged Children) were conducted with the mothers when the child was 3- and 5-years old (hereafter referred to as the In-Home Study). The Institutional Review Boards at Columbia University and Princeton University approved the FFCWS study procedures. The Wayne State University Institutional Review Board deemed the secondary analyses conducted for the current study exempt from oversight.

\section{Participants}

The current study focused on only those families from the FFCWS that completed the 3-years In-Home Study interview $(n=3,299) ; 161$ families were excluded because the father was in jail when the child was age 3 . Of the remaining 3,138 families, only 1,134 fathers were present in the home when the 5-years In-Home Study collected data on neglect. Notably, the large number of families without a residential biological father at the 5-years In-Home study is attributable to the FFCWS sampling design, which oversampled nonmarital births at baseline (Reichman et al., 2001). An additional 45 families were excluded because the mother did not complete the In-Home Study measures, yielding an analytic sample of 1,089 families.

\section{Measures}

Both fathers and mothers contributed core interview data. Time-invariant demographic variables were assessed at baseline. Fathers reported the following items: paternal characteristics of depression, heavy alcohol use, parenting stress, daily involvement with the child; report of relationship quality with the child's mother; and demographic characteristics such as age, education level, household income, and level of economic hardship. Mothers reported the following items: maternal characteristics of depression, heavy alcohol use, parenting stress; and father-to-mother physical aggression. Measures of child neglect, the study dependent measure, were assessed using mothers' reports of maternal and paternal neglect behaviors, and collected during the 5-years In-Home Study interview. Fathers were not eligible to participate in the additional 5-years In-Home Study component; however, if the father was residing in the home, then the In-Home interview asked the mother to report the father's behavior toward the target child. Prior research on the Parent to Child Conflict Tactics Scale (CTSPC) has indicated high, statistically significant correlations between fathers' self-report and mothers' reports of fathers' behaviors, with mothers and fathers agreeing more than $90 \%$ of time on the more serious CTSPC items (Lee, Lansford, Pettit, Bates, \& Dodge, in press).

Dependent variable: Child neglect incident by a parent. The CTSPC neglect subscale measures 5 types of physical or psychological child neglect by asking parents whether they engaged in behaviors toward their child within the past year (Straus, Hamby, Finkelhor, Moore, \& Runyan, 1998). Mothers indicated the actions they carried out (i.e., left child unattended by an adult; had been so involved in her own problems she could not express love for the child verbally or physically; was unable to ensure the child received adequate food; was unable to ensure the child had medical attention when needed; was so drunk or high that she had difficulty taking care of the child). Then, mothers were asked to respond to the same questions but indicating the actions the father had carried out toward the child. As might be expected, the community sample used in the current study had few reports of child neglect. Given this low base rate we coded any incident of neglect by the mother or father in the past year $(1=$ yes) versus no incident $(0=$ no $)$ (Lee, submitted for publication).

As with all forms of child maltreatment, obtaining accurate estimates of child neglect incidence is challenging. We chose not to rely on CPS reports for a number of reasons. First, because neglect is difficult to detect, CPS reports can underestimate the incidence of neglect particularly when it involves young children (Dubowitz et al., 2002). Furthermore, neglectful parenting behaviors such as those measured by the CTSPC have been linked to poor outcomes for children (Hildyard \& Wolfe, 2002; Sedlak \& Broadhurst, 1996). Second, maltreatment type (i.e., physical, sexual, and neglect) is misclassified in up to $25 \%$ of CPS reports, rendering these reports questionable indicators when focusing on neglect rather than all forms of maltreatment (Runyan et al., 2005). Third, emotional neglect is unlikely to be captured by substantiated CPS reports. Hence, we chose to 
use a reliable and valid measure of neglect that assesses parental behaviors such as leaving a child home alone and failing to provide adequate food (Straus et al., 1998), which are among the most common forms of child neglect (Hussey, Chang, \& Kotch, 2006) and would warrant CPS attention for children $\leq 5$ years. Although CTSPC does not capture all potential forms of child neglect, research examining the impact of child neglect on adolescent development has demonstrated that specific subtypes of neglect do not differentially explain children's neglect experiences, nor do different subtypes of neglect differentially predict child outcomes (Mennen, Prindle, \& Trickett, 2011). Furthermore, research has shown the CTSPC measure is correlated with household CPS involvement; similar patterns of risk and protective factors were found in a comparison of households' CTSPC neglect scores and CPS reports of neglect (Slack et al., 2011).

Key predictor variable: Paternal depression. The Composite International Diagnostic Interview-Short Form (CIDI-SF), Section A (Kessler, Andrews, Mroczek, Ustun, \& Wittchen, 1998) was used to measure major depression through self-reports collected from both parents at the interview when the child was 3-years old. The CIDI-SF is a standardized instrument that uses the criteria set forth in the Diagnostic and Statistical Manual of Mental Disorders (DSM-IV) to determine the probability that the respondent would be diagnosed with major depression if given the full CIDI interview. Major depression is indicated by self-report of feelings of depression or anhedonia that are experienced for most of the day, every day, for at least 2 weeks. Respondents who answered affirmatively to questions about depressive symptoms were asked probes about losing interest, feeling tired, change in weight, trouble sleeping, difficulty with concentrating, feeling worthless, and thinking about death. In the current study, participants were classified as likely to have major depression if they endorsed the screening items and 3 or more depressive symptoms $(0=$ no, $1=$ yes $)$.

Other parenting risks. During the 3-year core interview, mothers and fathers self-reported parenting risk variables, including heavy alcohol use and perceived parenting stress. Heavy alcohol use is included because this behavior can both produce and result from depressive symptoms. A dichotomous variable was created to indicate heavy alcohol use by assessing whether the father or mother had consumed $\geq 4$ drinks in 1 day in the past 12 months $(0=$ consumed $0-3$ drinks in 1 day in the past year or $1=$ consumed $\geq 4$ drinks in 1 day in the past year). The FFCWS alcohol use questions are based on the CIDI-SF alcohol dependence questions, which are intended to provide the probability or likelihood that the respondent would receive a diagnosis of alcohol dependent had they received the full CIDI. However, few men or women in the FFCWS met the CIDISF criteria indicating probability of alcohol dependence. Therefore, we created a less stringent variable to indicate "heavy alcohol use." Though less stringent than the CIDI-SF, our operationalization of heavy alcohol use approximates the National Institute on Alcohol and Alcoholism's definition of a "heavy drinking day," as indicated by $\geq 5$ drinks in a single day for men and $\geq 4$ drinks in a single day for women (National Institute on Alcohol Abuse and Alcoholism, 2005).

Perceived parenting stress was measured using the Parent Stress Index-Short Form (Abidin, 1995). Parents indicate their level of agreement with 4 statements, such as "I feel trapped by my responsibilities as a parent" and "being a parent is harder than I thought it would be." Responses were coded as a continuous variable ranging from 1 (lowest stress) to 4 (most stress) $(\alpha=.62)$.

Also during the 3-year core interview, fathers provided self-reports of their daily involvement with the child. A mean score indicated the number of days per week $(0=$ never to $7=$ every day $)$ the father provided 13 different types of care to the child. Examples of father-provided care included the following: sings songs or nursery rhymes with child, hugs or shows physical affection to child, tells child that he loves him or her, reads stories to child, assists child with eating, and puts child to bed $(\alpha=.89)$.

Assessment of father-to-mother physical aggression was based on maternal reports obtained during the 3-year core interview. Using items from the revised Conflict Tactics Scale, mothers were asked to indicate whether the father had slapped or kicked her, hit her with a fist or an object, or tried to make her have sex or sexual contact when she did not want sexual contact (Straus, Hamby, Boney-McCoy, \& Sugarman, 1996). Fathers were asked to report on the perceived quality of their relationship with the child's mother using a 5 -point scale $(1=$ poor, 2 = fair, $3=$ good, 4 =very good, and $5=$ excellent $)$. In our analysis, we controlled for the quality of the parental relationship to address concerns about the potential for a mother's report of child neglect to be influenced by the quality of the mother-father relationship.

Household economic hardship. Questions regarding economic hardship asked about events that occurred during the 12 months before the core interview when the child was 3-years old. Measures included paternal employment status, annual household income, and an index of economic hardship. The index of economic hardship was created by summing the following dichotomous variables: (1) whether the family received financial assistance from nongovernmental sources (e.g., relatives, friends), (2) governmental sources (e.g., welfare, food stamps, unemployment benefits) or (3) had the electricity turned off due to failure to pay the bill in the past year. Annual household income (mean $=\$ 53,555 ; \mathrm{SD}=\$ 43,239 ;$ median $=\$ 43,000$ ) was log transformed in regression analyses to reduce skew.

\section{Data analytic plan}

Table 1 presents sample characteristics and bivariate results with Bonferroni-corrected post hoc tests (i.e., $\chi^{2}$ and 1 -way analysis of variance) to assess differences in the independent variables as a function of neglect. Table 2 presents adjusted odds ratios (AOR) and 95\% confidence intervals (CI) for multivariate logistic regression analyses examining predictors of child 
neglect. Model 1 focused on fathers' socio-demographic and psychosocial factors and examined paternal parenting risks, relationship quality, and household economic hardship, while controlling for demographic characteristics and economic contributions of the father, as well as child gender. Model 2 examines whether the relationships observed in model 1 when including only paternal predictor variables remain after addition of variables to control for maternal parenting risks (depression, heavy alcohol use, and parenting stress) that are known to increase risk for neglect.

Although sample weights are available for the core FFCWS interviews to adjust the data to be nationally representative, the use of sample weights in this study was inappropriate for several reasons. First, sample weights are not available for the In-Home Study. Second, families were selected into this study based on father involvement, which creates a bias in the sample toward families that are more advantaged on economic indicators. Third, the study focus was to provide estimates of risk for child neglect using regression analyses, which can be made inefficient by sampling weights. Hence, in regression analyses of our unweighted data, we instead accounted for clustering by interview city and parental marital status at birth, key factors in the FFCWS sampling design, as recommended elsewhere (Korn \& Graubard, 1991).

\section{Results}

Approximately $12 \%$ of families reported at least 1 instance of neglect: by the father only (2.9\%), the mother only (3.6\%), or both parents (5.4\%). About $10 \%$ of fathers and $16 \%$ of mothers were depressed when their child was 3-years old. Neglect was associated with paternal and maternal depression and stress, father-to-mother physical aggression (marginally significant), fathers' lower rating of relationship quality with mothers, and lower annual household income (Table 1).

Table 1

Sample characteristics, by child negect at 5-years of age.

\begin{tabular}{|c|c|c|c|c|}
\hline Variable (range) & $\begin{array}{c}\text { Full sample } \\
N=1,089(100 \%) \\
\% \text { or } M(\mathrm{SD})\end{array}$ & $\begin{array}{c}\text { Neglect }- \text { no }^{\mathrm{a}} \\
n=960(88.15 \%) \\
\% \text { or } M(\mathrm{SD})\end{array}$ & $\begin{array}{c}{\text { Neglect }- \text { yes }^{\mathrm{a}}}^{n=129(11.85 \%)} \\
\% \text { or } M(\mathrm{SD})\end{array}$ & $P$-Value ${ }^{\mathrm{b}}$ \\
\hline Paternal depression, $y$ & 10.3 & 9.1 & 19.4 & $<.001$ \\
\hline Paternal heavy alcohol use, $y$ & 30 & 30 & 29 & .71 \\
\hline Paternal parenting stress (1-4) & $2.04(.66)$ & $2.02(.65)$ & $2.24(.68)$ & $<.001$ \\
\hline $\begin{array}{l}\text { Paternal daily involvement with } \\
\text { child }(0-7)\end{array}$ & $4.47(1.09)$ & $4.49(1.09)$ & $4.32(1.11)$ & .10 \\
\hline Maternal depression, $y$ & 15.7 & 14.0 & 28.7 & $<.001$ \\
\hline Maternal heavy alcohol use, $y$ & 10.5 & 10.1 & 13.2 & .28 \\
\hline Maternal parenting stress (1-4) & $2.2(.63)$ & $2.2(.63)$ & $2.5(.58)$ & $<.001$ \\
\hline $\begin{array}{l}\text { Father-to-mother physical } \\
\text { aggression, } y\end{array}$ & 2.0 & 1.8 & 4.2 & .08 \\
\hline $\begin{array}{l}\text { Father's report of relationship } \\
\text { quality with mother (1-5) }\end{array}$ & $4.20(.87)$ & $4.21(.86)$ & $4.06(.92)$ & .05 \\
\hline $\begin{array}{l}\text { Annual household income } \\
\qquad(1-370,000)^{\mathrm{c}}\end{array}$ & $53,555(43,239)$ & $54,829(43,976)$ & $44,101(36,077)$ & $<.01$ \\
\hline $\begin{array}{l}\text { Household financial hardship in } \\
\text { past year }{ }^{d}\end{array}$ & & & & .51 \\
\hline No financial hardship & 62.8 & 63.4 & 58.6 & \\
\hline 1 type of financial hardship & 29.3 & 28.7 & 33.6 & \\
\hline $2+$ types of financial hardship & 7.9 & 8.0 & 7.8 & \\
\hline Paternal age (15-61) & $29.42(7.04)$ & $29.53(7.11)$ & $28.64(6.47)$ & .18 \\
\hline Paternal educational level & & & & .55 \\
\hline Less than high school degree & 25.9 & 25.3 & 29.9 & \\
\hline High school degree or equivalent & 27.5 & 27.3 & 29.1 & \\
\hline Some college & 26.7 & 27.2 & 22.8 & \\
\hline College degree or higher & 19.9 & 20.2 & 18.1 & \\
\hline Paternal race or ethnicity & & & & .21 \\
\hline White (non-Hispanic) & 32.3 & 33.3 & 24.8 & \\
\hline African American & 35.4 & 35.2 & 36.4 & \\
\hline Hispanic & 28.6 & 27.8 & 34.1 & \\
\hline Other & 3.8 & 3.7 & 4.7 & \\
\hline $\begin{array}{l}\text { Paternal current employment } \\
\text { status, } y\end{array}$ & 88.0 & 87.8 & 89.2 & 65 \\
\hline Marital birth, $y$ & 46.8 & 47.7 & 40.3 & .11 \\
\hline Male child, $y$ & 52.1 & 52.5 & 48.8 & .43 \\
\hline
\end{tabular}

a Not all cell percentages add to $100 \%$ because of rounding; $y=$ yes.

b Bonferroni-corrected one-way analysis of variance (ANOVA) for continuous variables or Pearson $\chi^{2}$ omnibus test for categorical variables.

c Median annual total household income $=\$ 43,000$.

d Created by summing three dichotomous variables: (1) whether the family received financial assistance from nongovernmental sources (e.g., relatives and friends), (2) governmental sources (e.g., welfare, food stamps, and unemployment benefits) or (3) had the electricity turned off due to failure to pay the bill in the past year. 
Table 2

Logic regression models of paternal and household characteristics at 3 years or earlier predicting child neglect at 5 years of age. ${ }^{\text {a }}$

\begin{tabular}{|c|c|c|c|c|}
\hline Variable & $\begin{array}{c}\text { Model } 1(n=1,004)^{\mathrm{b}} \\
\operatorname{AOR}(95 \% \mathrm{CI})\end{array}$ & $P$-Value & $\begin{array}{l}\text { Model } 2(n=1,002)^{\mathrm{b}} \\
\quad \operatorname{AOR}(95 \% \mathrm{CI})\end{array}$ & $P$-Value \\
\hline Paternal depression ${ }^{c}$ & $2.26(1.36-3.76)$ & .002 & $1.94(1.18-3.19)$ & .009 \\
\hline Paternal heavy alcohol use & $0.82(0.49-1.38)$ & .46 & $0.78(0.46-1.34)$ & .37 \\
\hline Paternal parenting stress ${ }^{\mathrm{d}}$ & $1.54(1.09-2.16)$ & .01 & $1.40(0.97-2.04)$ & .075 \\
\hline Paternal daily involvement with child ${ }^{\mathrm{d}}$ & $0.88(0.78-1.00)$ & .055 & $0.89(0.78-1.04)$ & .14 \\
\hline Maternal depression $^{\mathrm{c}}$ & - & - & $1.71(1.05-2.78)$ & .03 \\
\hline Maternal heavy alcohol use ${ }^{d}$ & - & - & $1.44(0.73-2.85)$ & .10 \\
\hline Maternal parenting stress ${ }^{\mathrm{d}}$ & - & - & $1.70(1.22-2.36)$ & $<.001$ \\
\hline Father-to-mother physical aggression ${ }^{\mathrm{c}}$ & $2.44(0.91-6.59)$ & .08 & $1.51(0.48-4.71)$ & .30 \\
\hline Father's report of relationship quality with mother ${ }^{d}$ & $0.85(0.68-1.07)$ & .17 & $0.87(0.69-1.10)$ & .25 \\
\hline Annual household income & $1.00(0.99-1.00)$ & .066 & $1.00(0.99-1.00)$ & .14 \\
\hline \multicolumn{5}{|l|}{ Financial hardship ${ }^{\mathrm{e}}$} \\
\hline 1 type of financial hardship & $1.11(0.75-1.64)$ & .61 & $1.06(0.73-1.55)$ & .75 \\
\hline $2+$ types of financial hardship & $0.67(0.24-1.99)$ & .49 & $0.64(0.23-1.75)$ & .38 \\
\hline
\end{tabular}

AOR, adjusted odds ratio; $\mathrm{CI}$, confidence interval.

a From the final study sample of 1,089 families, there was less than $1 \%$ of missing data except for parental relationship quality (1.19\%) and father-to-mother physical aggression (5.6\%), resulting in $n=1,004$ for model 1 and $n=1,002$ for model 2 .

b Model was adjusted for 2 key variables used in the sampling design: marital status at birth (married or unmarried) and city. Both models controlled for paternal age, paternal educational level, paternal race or ethnicity, paternal current employment status, and male child.

c Dichotomous variable coded $0=$ no and $1=$ yes.

Higher scores indicate higher levels of the construct.

e Reference group is no financial hardship in the prior year.

Our first multivariable logistic regression (Table 2, model 1) shows fathers' depression when the child is age 3 is associated with more than double the odds of neglect of the child at age 5 [AOR: 2.26 (95\% CI: 1.36-3.76); $P<.01$ ]. Paternal parenting stress was also a significant risk factor for parental neglect of the child, raising the odds of neglect by $50 \%$ [AOR: 1.54 ( $95 \%$ CI: 1.09-2.16); $P<.01$ ]. However, positive paternal daily involvement was a protective factor, with higher levels of father involvement marginally significantly associated with less risk for child neglect [AOR: $0.88(95 \% \mathrm{CI}: 0.78-1.00)$; $P=.055$ ].

Maternal depression [AOR: 1.71 (95\% CI: 1.05-2.78); $P<.05$ ] and maternal parenting stress [AOR: 1.70 (95\% CI: 1.22-2.36); $P<.001]$ were also significantly associated with risk for neglect (Table 2, model 2). However, even after the addition of maternal parenting risk variables, paternal depression was still associated with nearly double the odds of child neglect [AOR: 1.94 (95\% CI: 1.18-3.19); $P<.01$ ] and paternal parenting stress continued to raise the odds of neglect by $40 \%$ but was only marginally statistically significant [AOR: 1.40 (95\% CI: 0.97-2.04); $P=.075$ ]. Although the AOR for positive paternal daily involvement with the child changed only slightly in model 2 [AOR: 0.89 (95\% CI: 0.78-1.04); $P=.14$ ], it was no longer significantly associated with neglect after including maternal parenting risks in the model.

\section{Discussion}

Both the consequences and etiology of child maltreatment have often been understood through the lens of a developmental-ecological framework (Belsky, 1984), which proposes that risk for child maltreatment is influenced by individual-level parental characteristics, family-level factors, and the broader social context. Although disentangling the mechanisms by which fathers may be involved in these processes is challenging, such efforts are important given the potential for identifying opportunities for intervention and prevention of maltreatment.

We found the rates of paternal and maternal depression to be twice as high in families that reported neglectful behaviors as compared with families that reported no incidents of such behaviors. Even when controlling for the strong and significant associations of maternal depression and parenting stress (Slack et al., 2011), paternal depression was linked to the neglect of young children. In fact, the magnitude of the effect for paternal depression was slightly stronger than the effect for maternal depression.

That paternal parenting stress and positive paternal daily involvement with the child ceased to be significant in model 2 may indicate that some of the positive (or negative) influence that fathers wield in predicting risk for maltreatment are accounted for by fathers' influence on mothers' ability to parent the child well (Guterman, Lee, Lee, Waldfogel, \& Rathouz, 2009). For example, positive father involvement and provision of resources may minimize maternal parenting stress and contribute to her parental functioning (Coley \& Schindler, 2008). As seen in prior research, positive father involvement minimized the negative consequences of maternal depression on children (Mezulis et al., 2004).

It is important to note that our sample included only those fathers living in the same household as their children, and as such, was biased toward families with greater economic advantages (Carlson \& McLanahan, 2010; Guzzo \& Lee, 2008). This bias likely resulted in lower rates of child neglect than might be observed in either more disadvantaged families or single-parent households. However, nearly $12 \%$ of mothers in our sample indicated that she or the father had engaged in at least 1 of 5 neglectful behaviors of their young child in the past year. This incidence rate falls within the range (11-30\%) of neglectful behaviors found in an observational study of fathers and child neglect among urban families that included 
single-parent households (Dubowitz, Black, Kerr, Starr, \& Harrington, 2000), suggesting that neglect of young children may be common even in families with relatively fewer economic or demographic risk factors for neglect.

\section{Implications for intervention}

Prenatal and perinatal clinic visits provide an important opportunity to screen for paternal depression and such screening efforts have been critical in addressing maternal depression (Dubowitz, Feigelman, Lane, \& Kim, 2009; Olson, Dietrich, Prazar, \& Hurley, 2006; Stowe, Hostetter, \& Newport, 2005). The World Health Organization recommends screening for depression in primary care settings, and most pediatricians strongly agree it is important to screen for parental mental health problems and to provide referral during pediatric visits (Flaherty \& Stirling, 2010). However, fathers' attendance at pediatric visits is often inconsistent (Garfield \& Isacco, 2006) and, perhaps as a result, screening efforts have largely focused on mothers (Dubowitz et al., 2009; Horwitz et al., 2007). Even so, father involvement and interest in early child development tends to be highest during infancy (Carlson \& McLanahan, 2002). Thus, from the perspective of early intervention to prevent child neglect, the "magic moment" following the birth of a child and early well-baby visits may provide a unique window of opportunity to not only stress the importance of fathers' engagement in pediatric visits but also to screen fathers for depression.

Pediatricians and social workers in pediatric health care settings can be trained to deliver information that may increase paternal engagement at prenatal and well-baby visits. The Safe Environment for Every Kid (SEEK) program is a comprehensive approach to the prevention of child neglect (Dubowitz et al., 2009). The SEEK program includes physician training in identifying and intervening with potential risk factors, parenting-risk screening questionnaire for mothers, and social work intervention and referral to community resources for those most in need (Dubowitz et al., 2009). Our findings point to the need to integrate father-focused content into interventions such as SEEK. Such information may include training physicians to engage fathers and to encourage fathers' attendance at pediatric well-baby visits, with subsequent opportunities for screening and opportunities for social work intervention as warranted. Similar efforts to implement screening and targeted intervention for fathers could be implemented in other comprehensive maltreatment prevention services, such as home visiting nurse programs.

Of course, it is also important to recognize that such efforts place additional demands on service providers who are being asked to do increasingly more with fewer resources. For cases in which comprehensive intervention is not possible, recent research has highlighted the effectiveness of brief, technology-based intervention. The text4baby program is 1 such example; text4baby provides expectant and new mothers with basic information about child care and development via text messaging (http://www.text4baby.org/). Another technology-delivered program delivered in primary care settings targets reduced substance use among postpartum women because substance use is a well-established risk factor for child neglect (Ondersma, Grekin, \& Svikis, 2011; Ondersma, Svikis, \& Schuster, 2007). The results of the current study suggest that encouraging mental health help-seeking behaviors among fathers may prevent child neglect, and technology based interventions may be one way to reach men who are unlikely to attend well-baby visits. Similar efforts that target fathers should provide information on paternal depression, as well as content to destigmatize mental health help-seeking behaviors and encourage father engagement in well-baby visits.

\section{Study strengths and limitations}

Among the particular strengths of this study are its large community-based sample and the rigor of the study design, which enabled prospective analyses of individual-level paternal characteristics and family-level factors while controlling for household economic conditions and paternal demographic factors. Few prior studies have used longitudinal, prospective data with a large number of families to examine paternal mental health and risk for child neglect while accounting for well-known maternal parenting risks. However, the study has some limitations.

The findings of this study are limited to urban-dwelling biological fathers living with their young children. Results may not generalize to families with father surrogates, nonresidential fathers, or families living in nonurban areas.

Measuring the occurrence of child neglect is challenging in all population-based (vs. clinic-based) studies. To assess incidence of neglect in this study, we used the CTSPC because the instrument is a reliable and valid measure of neglect that taps into multiple dimensions of neglectful parenting. Moreover, the CTSPC captures a wider range of households at-risk for maltreatment than could be obtained using unidimensional accounts, such as CPS involvement (Dubowitz et al., 2002; Runyan et al., 2005; Slack et al., 2011; Straus et al., 1998). The CTSPC assesses the 2 most common neglectful parenting behaviors-failure to supervise and failure to provide necessities-the combination of which represent the majority of child neglect cases. The CTSPC also captures emotional neglect, which is difficult to capture via CPS report. The CTSPC measure of neglect may have improved external validity in comparison to CPS reports. One recent study showed similar patterns of risk and protective factors when comparing CPS reports to maternal self-report using the CTSPC neglect subscale (Slack et al., 2011). Hence, the CTSPC is a reasonable tool for assessing risk for child neglect in a population-based study even in the absence of corroborating CPS reports.

Similar to other studies that have used an outside source such as maternal reports (Berger et al., 2009; Slack et al., 2011; Theodore, Runyan, \& Chang, 2007), we relied on the child's mother to ascertain household neglect. Prior research using the CTSPC has indicated high, statistically significant correlations between fathers' self-report and mothers' reports of fathers' behaviors, with mothers and fathers agreeing more than 90\% of time on the more serious CTSPC items (Lee et al., 
in press). In general, when comparing maternal reports of paternal behaviors to paternal self-report, fathers reported that they did each item slightly more frequently than was reported by the mothers, a finding that is consistent with the notion that mothers may not be aware of all instances of fathers' negative parenting behaviors. In the current study, a pattern of maternal underreporting would most likely bias the results toward null findings and provide an underestimate of study effects. While all self-report measures are potentially subject to reporting biases, there is reason to believe that mothers' reports of fathers' behaviors using the CTSPC are valid and consistent with fathers' self-reports (Lee et al., in press).

\section{Conclusions}

Child neglect results from a constellation of interrelated, but distinct, problems such as poverty and parenting risk factors (Dubowitz et al., 2005). The results of this study suggest that paternal depression plays an important, independent role in risk for child neglect in father-involved families. These findings underscore the need to screen both fathers and mothers for parenting risk factors associated with child neglect, including depression. Increased efforts may be needed to educate pediatricians and social work professionals who work with families to deliver information intended to engage fathers in pediatric visits. Ongoing efforts in pediatric health care settings to screen mothers for depression should be adapted to include screening for fathers. Technology-enhanced interventions may be an especially promising approach to reach and engage fathers of young children.

\section{References}

Abidin, R. (1995). Parent stress inventory (3rd ed.). Odessa, FL: Psychological Assessments Resources.

Belsky, J. (1984). The determinants of parenting: A process model. Child Development, 55(1), 83-96.

Berger, L. M., Paxson, C., \& Waldfogel, J. (2009). Mothers, men, and child protective services involvement. Child Maltreatment, 14(3), 263-276.

Brewster, A. L., Nelson, J. P., Hymel, K. P., Colby, D., Lucas, D. R., McCanne, T. R., \& Milner, J. S. (1998). Victim, perpetrator, family, and incident characteristics of 32 infant maltreatment deaths in the United States Air Force. Child Abuse E Neglect, 22, 91-101.

Carlson, M., \& McLanahan, S. (2002). Fragile families, father involvement and public policy. In C. S. Tamis-LeMonda, \& N. Cabrera (Eds.), Handbook of father involvement: Multidisciplinary perspectives (pp. 461-488). Mahwah, NJ: Lawrence Erlbaum Associates.

Carlson, M. J., \& McLanahan, S. S. (2010). Fathers in fragile families. In M. E. Lamb (Ed.), The role of the father in child development. NJ: Wiley \& Sons.

Coley, R. L., \& Schindler, H. S. (2008). Biological fathers' contributions to maternal and family functioning. Parenting: Science and Practice, 8, $294-318$.

Coohey, C. (1998). Home alone and other inadequately supervised children. Child Welfare, 77(3), 291-310.

Davé, S., Nazareth, I., Senior, R., \& Sherr, L. (2008). A comparison of father and mother report of child behaviour on the strengths and difficulties questionnaire. Child Psychiatry and Human Development, 39, 399-413.

Davé, S., Peterson, I., Sherr, L., \& Nazareth, I. (2010). Incidence of maternal and paternal depression in primary care. Archives of Pediatric and Adolescent Medicine, 164(11), 1038-1044.

Davis, R. N., Davis, M. M., Freed, G. L., \& Clark, S. J. (2011). Fathers' depression related to positive and negative parenting behaviors with 1-year old children. Pediatrics, 127(4), 611-619.

DeVooght, K., McCoy-Roth, M., \& Freudlich, M. (2011). Young and vulnerable: Children five and under experience high maltreatment rates. Early Childhood Highlights, 2(2), 1-20.

Dierker, L. C., Merikangas, K. R., \& Szatmari, P. (1999). Influence of parental concordance for psychiatric disorders on psychopathology in offspring. Journal of the American Academy of Child E' Adolescent Psychiatry, 38(3), 280-288.

Dubowitz, H., Black, M. M., Kerr, M. A., Starr, R. H., Jr., \& Harrington, D. (2000). Fathers and child neglect. Archives of Pediatrics E Adolescent Medicine, 154, $135-141$.

Dubowitz, H., Feigelman, S., Lane, W., \& Kim, J. (2009). Pediatric primary care to help prevent child maltreatment: The Safe Environment for Every Kid (SEEK) model. Pediatrics, 123, 858-864.

Dubowitz, H., Kim, J., Black, M. M., Weisbart, C., Semiatin, J., \& Magder, L. S. (2011). Identifying children at high risk for a child maltreatment report. Child Abuse E Neglect, 35, 96-104.

Dubowitz, H., Newton, R. R., Litrownik, A. J., Lewis, T., Briggs, E. C., Thompson, R., English, D., Lee, L. C., \& Freerick, M. M. (2005). Examination of a conceptual model of child neglect. Child Maltreatment, 10(2), 173-189.

Dubowitz, H., Papas, M. A., Black, M. M., \& Starr, R. H. (2002). Child neglect: Outcomes in high-risk urban preschoolers. Pediatrics, $109(6), 1100-1107$.

Elgar, F. J., Mills, R. S. L., McGrath, P. J., Waschbusch, D. A., \& Brownridge, D. A. (2007). Maternal and paternal depressive symptoms and child maladjustment: The mediating role of parental behavior. Journal of Abnormal Child Psychology, 35(6), 943-955.

English, D. J., Thompson, R., Graham, J. C., \& Briggs, E. C. (2005). Toward a definition of neglect in young children. Child Maltreatment, 10(2), $190-206$.

Flaherty, E. G., \& Stirling, J., Jr. (2010). The pediatrician's role in child maltreatment prevention. Pediatrics, 126, $833-841$.

Fujiwara, T., Barber, C., Schaechter, J., \& Hemenway, D. (2009). Characteristics of infant homicides: Findings from a US multisite reporting system. Pediatrics, 124, e210-e217.

Garfield, C. F., \& Isacco, A. (2006). Fathers and the well-child visit. Pediatrics, 117, e637-e645.

Gilbert, R., Widom, C. S., Brown, K., Fergusson, D. M., Webb, E., \& Janson, S. (2009). Burden and consequences of child maltreatment in high-income countries. The Lancet, 373, 68-81.

Guterman, N. B., Lee, Y., Lee, S. J., Waldfogel, J., \& Rathouz, P. J. (2009). Fathers and maternal risk for physical child abuse. Child Maltreatment, 14, 277-290.

Guzzo, K. B., \& Lee, H. (2008). Couple relationship status and patterns in early parenting practices. Journal of Marriage and Family, 70(1), 44-61.

Hildyard, K. L., \& Wolfe, D. A. (2002). Child neglect: Developmental issues and outcomes. Child Abuse E' Neglect, $26,679-695$.

Hindley, N., Ramchandani, P. G., \& Jones, D. P. H. (2006). Risk factors for recurrence of maltreatment: A systematic review. Archives of Diseases in Childhood, 91, 744-752.

Horwitz, S. M., Kelleher, K. J., Stein, R. E. K., Storfer-Isser, A., Youngstrom, E. A., Park, E. R., Heneghan, A. M., Jensen, P. S., O’Connor, K. G., \& Hoagwood, K. E. (2007). Barriers to the identification and management of psychosocial issues in children and maternal depression. Pediatrics, 119, E201-E208.

Hussey, J. M., Chang, J. J., \& Kotch, J. B. (2006). Child maltreatment in the United States: Prevalence, risk factors, and adolescent health consequences. Pediatrics, 118(3), 933-942.

Jones, L. M., Finkelhor, D., \& Halter, S. (2006). Child maltreatment trends in the 1990: Why does neglect differ from sexual and physical abuse? Child Maltreatment, 11(2), 107-120.

Kahn, R. S., Brandt, D., \& Whitaker, R. C. (2004). Combined effect of mothers' and fathers' mental health symptoms on children's behavioral and emotional well-being. Archives of Pediatric and Adolescent Medicine, 158, 721-729.

Kessler, R. C., Andrews, G., Mroczek, D., Ustun, B., \& Wittchen, H. U. (1998). The World Health Organization Composite International Diagnostic Interview Short Form (CIDI-SF). International Journal of Methods in Psychiatric Research, 7(4), 171-185. 
Korn, E. L., \& Graubard, B. I. (1991). Epidemiologic studies utilizing surveys: Accounting for the sampling design. American Journal of Public Health, 81(9), 1166-1173.

Kotch, J. B., Lewis, T., Hussey, J. M., English, D., Thompson, R., Litrownik, A. J., \& Runyan, D. K. (2008). Importance of early neglect for childhood aggression. Pediatrics, 121, 725-731.

Lee, S. J. Paternal and household characteristics associated with child neglect and child protective services involvement, submitted for publication.

Lee, S. J., Lansford, J. E., Pettit, G. S., Bates, J. E., \& Dodge, K. A. (in press). Parental agreement of reporting parent to child aggression using the Conflict Tactics Scales. Child Abuse \& Neglect, http://dx.doi.org/10.1016/j.chiabu.2012.04.005.

Lee, S. J., Perron, B. E., Taylor, C. A., \& Guterman, N. B. (2011). Paternal psychosocial characteristics and corporal punishment of their 3-year-old children. Journal of Interpersonal Violence, 26(1), 71-87.

Margolin, L. (1992). Child abuse by mothers' boyfriends: Why the overrepresentation? Child Abuse E Neglect, 16, $541-551$.

Mennen, F. E., Prindle, J., \& Trickett, P. K. (2011). Foster care as an intervention for neglect: Results from a multi-ethnic urban sample. Paper presented at the translational research on child neglect consortium, Iowa City, IA.

Mezulis, A. H., Hyde, J. S., \& Clark, R. (2004). Father involvement moderates the effect of maternal depression during a child's infancy on child behavior problems in kindergarten. Journal of Family Psychology, 18(4), 575-588.

National Institute on Alcohol Abuse and Alcoholism (2005). Helping patients who drink too much: A clinician's guide. Updated 2005 edition. Available from http://pubs.niaaa.nih.gov/publications/Practitioner/CliniciansGuide2005/clinicians_guide.htm.

Nobes, G., \& Smith, M. (2000). The relative extent of physical punishment and abuse by mothers and fathers. Trauma, Violence $\mathcal{E}$ Abuse, 1(1), 47-66.

Olson, A. L., Dietrich, A. J., Prazar, G., \& Hurley, J. (2006). Brief maternal depression screening at well-child visits. Pediatrics, 118, $207-216$.

Ondersma, S. J., Grekin, E. R., \& Svikis, D. S. (2011). The potential for technology in brief interventions for substance use and during-session prediction of computer-delivered brief intervention response. Substance Use \& Misuse, 46, 77-86.

Ondersma, S. J., Svikis, D. S., \& Schuster, C. R. (2007). Computer-based brief intervention: A randomized trial with postpartum women. American Journal of Preventive Medicine, 32(3), 231-238.

Paulson, J. F., Dauber, S., \& Leiferman, J. A. (2006). Individual and combined effects of postpartum depression in mothers and fathers on parenting behavior. Pediatrics, 118, 659-668.

Paulson, J. F., Keefe, H. A., \& Leiferman, J. A. (2009). Early parental depression and child language development. Journal of Child Psychology, 50(3), $254-262$.

Radhakrishna, A., Bou-Saada, I. E., Hunter, W. M., Catellier, D. J., \& Kotch, J. B. (2001). Are father surrogates a risk factor for child maltreatment? Child Maltreatment, 6(4), 281-289.

Ramchandani, P. G., Stein, A., O'Connor, T. G., Heron, J., Murray, L., \& Evans, J. (2008). Depression in men in the postnatal period and later child psychopathology: A population cohort study. Journal of the American Academy of Child and Adolescent Psychiatry, 47(4), 390-398.

Reichman, N. E., Teitler, J. O., Garfinkel, I., \& McLanahan, S. S. (2001). Fragile families: Sample and design. Children and Youth Services Review, 32, 303-326.

Runyan, D. K., Cox, C. E., Dubowitz, H., Newton, R. R., Upadhyaya, M., Kotch, J. B., Leeb, R. T., Everson, M. D., \& Knight, E. D. (2005). Describing maltreatment: Do child protective service reports and research definitions agree? Child Abuse $\mathcal{E}$ Neglect, 29(5), 461-477.

Schumacher, M., Zubaran, C., \& White, G. (2008). Bringing birth-related paternal depression to the fore. Women and Birth, $21,65-70$.

Sedlak, A. J., \& Broadhurst, D. D. (1996). Executive summary of the third National Incidence Study of Child Abuse and Neglect. Washington, DC: US Department of Health and Human Services, Administration of Children, Youth and Families, National Center on Child Abuse and Neglect.

Slack, K. S., Berger, L. M., Dumont, K., Yang, M. Y., Kim, B., Ehrhard-Dietzel, S., \& Holl, J. L. (2011). Risk and protective factors for child neglect during early childhood: A cross-study comparison. Children and Youth Services Review, 33(8), 1354-1363.

Stiffman, M. N., Schnitzer, P. G., Adam, P., Kruse, R. L., \& Ewigman, B. G. (2002). Household composition and risk of fatal child maltreatment. Pediatrics, 109, $615-621$.

Stowe, Z. N., Hostetter, A. L., \& Newport, D. J. (2005). The onset of postpartum depression: Implications for clinical screening and primary care. American Journal of Obstetrics and Gynecology, 192(2), 522-526.

Straus, M. A., Hamby, S. L., Boney-McCoy, S., \& Sugarman, D. B. (1996). The Revised Conflict Tactics Scale (CTS2): Development and preliminary psychometric data. Journal of Family Issues, 17, 283-316.

Straus, M. A., Hamby, S. L., Finkelhor, D. W., Moore, D. W., \& Runyan, D. (1998). Identification of child maltreatment with the Parent-Child Conflict Tactics Scales: Development and psychometric data for a national sample of American parents. Child Abuse E Neglect, 22, 249-270.

Theodore, A., Runyan, D., \& Chang, J. J. (2007). Measuring the risk of physical neglect in a population-based sample. Child Maltreatment, 12 (1), 96-105.

US Department of Health and Human Services, Administration for Children and Families, Administration on Children, Youth and Families, Children's Bureau (2010). Child maltreatment 2009. Available from http://www.acf.hhs.gov/programs/cb/stats_research/index.htm\#can.

Vogel, C. A., Boller, K., Faerber, J., Shannon, J. D., \& Tamis-LeMonda, C. S. (2003). Understanding fathering: The Early Head Start Study of Fathers of Newborns. New York: Ford Foundation.

Wanless, S. B., Rosenkoetter, S. E., \& McClelland, M. M. (2008). Paternal depression and infant cognitive development: Implications for research and intervention. Infants \&' Young Children, 21(2), 134-141.

Whitaker, R. C., Phillips, S. M., Orzol, S. M., \& Burdette, H. L. (2007). The association between maltreatment and obesity among preschool children. Child Abuse E' Neglect, 31(11-12), 1187-1199.

Wu, S. S., Ma, C. X., Carter, R. L., Ariet, M., Feaver, E. A., Resnick, M. B., \& Roth, J. (2004). Risk factors for infant maltreatment: A population-based study. Child Abuse E' Neglect, 28, 1253-1264. 